\title{
ANALISIS KECELAKAAN KERJA DENGAN MENGGUNAKAN METODE HFACS PADA PT. $X$
}

\author{
Ratna Ayu Ratriwardhani \\ Keselamatan dan Kesehatan Kerja, Universitas Nahdlatul Ulama Surabaya \\ Email: ratna.ayu@unusa.ac.id atau ratna.ratriwardani@yahoo.com
}

\begin{abstract}
PT. $X$ is a fabrication and manufacturing company which producing boiler in Surabaya, East Java. There are 50 accident cases happen in 2015-2019 based on accident report data that have been documented by PT. X's Environment Health Safety Officer (EHS). There are several causes of the past accident that already happen but the repetitious accidents have almost the same cause all the time it happen. Even though EHS already do the investigation toward the causes of the accident but it still happen repeatedly. The repetitious accident prove that there will be another unidentified factor or uneffective recommendation from the past analysis. Human Factors Analysis and Classification System (HFACS) is a accident analysis's tools of Human Factor aspect. This method was develop by Wiegmann and Shappell on 2003 and based on Swiss Cheese model. HFACS prove that accident happen because of failure on unsafe acts such as skill based errors, decision errors, perceptual errors, routine, exceptional. Another failure on precondition unsafe acts are physical environment, technological environment, crew resource management, adverse mental states, adverse physiological states. The deviation on unsafe supervision step are inadequate supervision, failure to correct problem, supervisory violation. The last step is defining failure on organizational influences such as resource management, and organizational process. There is an association on the step of resource management and supervisory violation based on the result of contingency coefficient test. Contingency coefficient test shows that almost all the failure affect failure on another level. It conclude that controlling action can't be charged only on management but also on all element involve so human error accident can be prevented.
\end{abstract}

Keywords: HFACS, Human Factors Analysis and Classification System, Accident

\begin{abstract}
ABSTRAK
PT. X merupakan perusahaan yang bergerak di bidang fabrikasi dan manufaktur penghasil boiler yang terletak di Surabaya Jawa Timur. Sesuai dengan data laporan kecelakaan yang didokumentasikan oleh Environment Health Safety Officer (EHS) PT. X selama tahun 2015-2019 terdapat 50 kasus kecelakaan. Dari beberapa kasus yang telah terdokumentasi oleh EHS tersebut, terdapat beragam penyebab, ada beberapa kasus kecelakaan yang terjadi berulang kali dengan penyebab yang hampir sama. Bahkan telah dilakukan investigasi setelah terjadinya kecelakaan namun kecelakaan masih saja berulang. Hal ini membuktikan bahwa terdapat faktor lain yang tidak teridentifikasi atau adanya rekomendasi yang tidak efektif dari analisa yang telah dilakukan. Metode Human Factors Analysis and Classification System (HFACS) adalah suatu alat analisa kecelakaan yang digunakan untuk menganalisa suatu kecelakaan pada aspek Human Factor. Metode ini
\end{abstract}


dikembangkan oleh Wiegmann dan Shappell pada tahun 2003. Metode ini didasarkan oleh model Swiss Cheese. Hasil analisis kecelakaan menggunakan metode HFACS, telah dibuktikan bahwa kecelakaan yang terjadi dikarenakan adanya kegagalan pada tindakan tidak aman yaitu kesalahan yang terjadi karena skill, kesalahan pengambilan keputusan, salah persepsi, pelanggaran yang dilakukan secara rutin, pelanggaran luar biasa. Berikutnya, kegagalan pada pre kondisi untuk tindakan tidak aman yaitu lingkungan fisik, lingkungan kerja (teknologi), crew resource management, mental yang merugikan perusahaan, fisik yang merugikan perusahaan. Selanjutnya, pada tahapan pengawasan yang membahayakan yaitu pengawasan yang tidak memadai, pengawasan yang gagal untuk mengetahui masalah, pelanggaran pengawasan. Tahapan yang terakhir adalah organisasi yaitu sumber daya manajemen, dan proses dalam organisasi. Hasil uji koefisien kontingensi terdapat asosiasi pada tahapan sumber daya manajemen dan pelanggaran pengawasan. Hasil uji kontingensi menunjukkan bahwa pada kasus ini hampir semua kegagalan mempengaruhi kegagalan di tingkat lain. Dengan demikian maka sebaiknya tidak hanya manajemen yang dikontrol, melainkan semua elemen yang berpengaruh harus tetap dikontrol sehingga dapat mencegah terjadinya kecelakaan yang disebabkan oleh human error.

Kata kunci: HFACS, Human Factors and Classification System, Kecelakaan Kerja.

\section{PENDAHULUAN}

Seirama dengan derap langkah pembangunan negara dewasa ini, kita akan mewujudkan industri yang maju dan mandiri dalam rangka mewujudkan Era industrialisasi. Proses industrialisasi maju ditandai antara lain dengan mekanisme, elektrifikasi dan modernisasi. ${ }^{1}$

PT. X adalah perusahaan di bidang manufaktur dengan pelayanan yang dilakukan yaitu mulai dari pengepakan hingga perakitan Boiler dan HRSG's. Kapasitas produksi PT. X adalah 600.000 Mhrs (6000 ton/thn). Perusahaan ini memiliki 500 karyawan dan 1500 karyawan subkontraktor. PT.X ini memiliki tujuh unit produksi dimana masing-masing unit memiliki proses kerja tertentu untuk membuat masingmasing komponen yang nantinya akan dirangkai menjadi boiler. Dalam keadaan demikian maka sumber bahaya pasti ada dan beragam. Adanya sumber bahaya maka potensi terjadinya kecelakaan akan timbul dan juga beragam.

Sesuai dengan data laporan kecelakaan yang didokumentasikan oleh Environment Health Safety Officer (EHS) PT. X selama tahun 2015-2019 terdapat 12 kasus kecelakaan untuk kategori loss time accident (LTA) dan 38 kasus kecelakaan untuk kategori First Aid Injury (FAI) yang terjadi di unit 1 (satu) hingga unit 7 (tujuh) PT. X. Dari beberapa kasus yang telah terdokumentasi oleh EHS tersebut, terdapat beragam penyebab, ada beberapa kasus kecelakaan yang terjadi berulang kali dengan penyebab yang hampir sama, bahkan telah dilakukan investigasi setelah terjadinya kecelakaan namun kecelakaan masih saja berulang. Contoh kasus yang terjadi berulang berdasarkan data yang telah terdokumentasi, yaitu: Kejadian terjadi pada 26 April 2011, korban yang berinisial FR melakukan 
pengangkatan dan penempatan panel sheet 33\#A Left 206. Setelah panel sheet tersebut ditempatkan pada jig harp assembly, yang bersangkutan bersama dengan rekannya (LX) menarik stik perentang dengan menggunakan dua tangannya. FR berada didepan LX. Karena stik perentang cukup berat $( \pm 60 \mathrm{~kg}$ ) saat stik terlepas dari salah satu ujung lack, maka terjadi ketidaksetimbangan sehingga stik terjungkit dan pada saat yang bersamaan posisi ibu jari tangan kiri korban tepat di bawah perentang kemudian terjepit diantara stik perentang dan perentangnya. Korban mendapat pertolongan medis di klinik perusahaan (08.30) lalu dirujuk ke RS untuk pertolongan lebih lanjut.

Dari kasus tersebut, menunjukkan kejadian terjadi berulang dengan penyebab yang hampir sama, dan membuktikan bahwa terdapat faktor pendukung lain yang menyebabkan terjadinya kecelakaan tersebut terjadi berulang atau adanya rekomendasi yang tidak efektif dari analisa yang telah dilakukan.

Untuk mengetahui adanya faktor pendukung lain atau rekomendasi yang tidak efektif dapat dilakukan tindakan pencegahan dengan menganalisa rekomendasi pada kecelakaan yang berulang dan melihat kegagalan pada segi Human Error agar kecelakaan tidak berulang lagi. Karena, telah diperkirakan bahwa $90 \%$ kecelakaan di tempat kerja disebabkan karena Human Error. ${ }^{2}$

Metode yang akan digunakan untuk menganalisis adalah metode HFACS. Metode
Human Factors Analysis and Classification System (HFACS) adalah suatu alat analisa kecelakaan yang digunakan untuk menganalisa pada Human Factors. Metode ini dikembangkan oleh Wiegmann dan Shappell pada tahun 2003 untuk analisis kecelakaan penerbangan militer dan sipil. Metode ini didasarkan oleh model Swiss Cheese.

Seperti namanya "swiss cheese", model ini merepresentasikan lubang pada sebuah keju. Lubang tersebut terdiri dari 4 (empat) tingkatan dimana masing-masing layer/tingkatan memiliki lubang kekeliruan atau kesalahan pada posisi yang acak, banyak dan besarnya ukuran lubang menunjukkan jumlah kemungkinan terjadinya kecelakaan. Meskipun metode ini awalnya dikembangkan untuk menganalisa kecelakaan pada penerbangan militer dan sipil, namun kelebihan dari metode ini adalah sifatnya yang general, sehingga dapat diterapkan di industri manapun (Human Factors guideline). Metode HFACS ini mencakup aspek individu dan organisasi, metode HFACS juga mudah dipelajari dan outputnya mudah ditafsirkan sehingga memudahkan peneliti untuk menganalisa kecelakaan yang terjadi.

Tujuan dari studi ini adalah untuk menganalisis kejadian berulang menggunakan HFACS, menganalisis hasil rekomendasi dari PT.X dan memberikan rekomendasi dari hasil analisis kejadian berulang menggunakan HFACS yang tepat kepada perusahaan sehingga dapat mencegah terjadinya kecelakaan. 


\section{METODE PENELITIAN}

\section{Tahap Identifikasi Awal}

Tahap identifikasi awal ini didasarkan oleh studi literatur dan studi lapangan yang telah diperoleh, beberapa urutan dari tahapan identifikasi awal adalah sebagai berikut:

\section{Identifikasi masalah}

Identifikasi beberapa permasalahan beru-pa kasus kecelakaan yang didapatkan pada saat melakukan studi lapangan pada PT. X.

2. Identifikasi Permasalahan dan Penentuan Tujuan

Merumuskan permasalahan sesuai dengan kondisi yang dihadapi perusahaan serta penetapan tujuan penelitian.

\section{Studi Pustaka}

Sebagai acuan dalam menentukan tahapan dalam berfikir untuk menyusun langkahlangkah penyelesaian permasalahan, dan menjadi pegangan dalam pengolahan data dan membantu dalam menginterprestasikan hasil dari pengolahan data.

4. Studi lapangan

Mengetahui kondisi seluruh proses yang ada di PT.X yang akan dijadikan bahan penelitian diperusahaan.

\section{Tahap Pengumpulan Data}

Dalam pengumpulan data ini diperlukan data primer dan sekunder. Data primer yang diperlukan adalah wawancara terhadap korban kecelakaan. Data sekunder yang diperlukan berupa laporan kecelakaan mulai tahun 20152019, serta dokumen-dokumen yang terkait tentang informasi dari accident, work instruction, dan job safety analysis.

\section{Tahap Pengolahan Data}

Penelitian ini akan mendeskripsikan peristiwa beserta rekomendasi dan mengkategorikan informasi. Pada tahapan ini peneliti mengidentifikasi kecelakaan yang telah di laporkan tahun 2015-2019.

\section{Tahap Analisa Data}

Peneliti melakukan analisa data berdasarkan data yang telah di investigasi. Peneliti mengumpulkan kecelakaan yang berulang dari accident report, kemudian masing-masing kecelakaan di kategorikan dan dianalisis menggunakan metode HFACS, selanjutnya peneliti menganalisis hubungan kegagalan pada tingkatan HFACS secara statistik menggunakan teori uji koefisien kontingensi (C) dengan menggunakan software yaitu SPSS.

Berikutnya peneliti melihat rekomendasi dari accident report guna membandingkan antara rekomendasi kecelakaan yang berulang. Peneliti menganalisis rekomendasi yang tidak efektif menggunakan metode HFACS sehingga dapat diketahui rekomendasi yang efektif yang dapat diberikan agar kecelakaan tidak terus berulang.

Parameter Human Factors Analysis And

\section{Classification Systems (HFACS)}

HFACS adalah suatu alat yang digunakan untuk menganalisis suatu kasus kecelakaan secara sistematis dan terorganisir. Pada HFACS yang dilihat bukan hanya dari sudut pandang 
unsafe acts of operator yang mengalami kecelakaan saja, namun juga mencakup tentang pre condition of unsafe acts, supervisory dan organisation influnces. HFACS melihat kepada semua aspek, jadi dapat diketahui dimana letak human factor yang sesungguhnya. HFACS juga dapat melihat hubungan kegagalan di tiap tingkatan HFACS. Parameter untuk mendukung penelitian yang dilakukan, mengacu pada:

1. Observasi Langsung

Melakukan pengamatan secara langsung ke objek penelitian untuk melihat dari dekat kegiatan yang dilakukan.

2. Wawancara

Cara pengumpulan data yang digunakan untuk memperoleh informasi langsung dari sumbernya.

3. Uji Koefisien Kontingensi (C)

Merupakan uji statistik nonparametris yang digunakan untuk menguji hipotesis asosatif. ${ }^{3}$ hubungan antar variabel bila datanya berbentuk nominal.

\section{HASIL DAN PEMBAHASAN}

\section{Analisa Kecelakaan Menggunakan HFACS}

Dari kasus-kasus yang terjadi pada PT. X dalam kurun waktu 5 tahun terakhir, peneliti memfokuskan analisa pada kecelakaan yang berulang. Dari 56 kasus kecelakaan yang terjadi pada PT. X terdapat 3 kecelakaan yang terjadi berulang dengan penyebab yang hampir sama. Dimana masing-masing peyebab lebih mengarah kepada persamaan jenis pekerjaan.

Untuk kasus pertama terjadi pada jenis pekerjaan pengangkatan manual, kasus kedua terjadi pada jenis pekerjaan lifting, dan kasus terakhir terjadi pada pekerjaan gerinda.

Berikut ini adalah tabel hasil analisis berdasarkan metode HFACS setelah dilakukan wawancara kepada korban.

Tabel 1. Analisa kecelakaan menggunakan HFACS pada kasus pertama

\begin{tabular}{|c|c|c|c|}
\hline \multicolumn{3}{|c|}{ Kriteria HFACS } & SW \\
\hline \multirow{5}{*}{$\begin{array}{l}\text { Unsafe Acts } \\
\text { of Operator }\end{array}$} & \multirow{3}{*}{ Errors } & Skill-Based Errors & Gagal untuk memprioritaskan perhatian \\
\hline & & Decision Errors & $\begin{array}{l}\text { Kurangnya pengetahuan sistem dan } \\
\text { prosedur }\end{array}$ \\
\hline & & Perceptual Errors & Salah persepsi untuk pengertian prosedur \\
\hline & \multirow[t]{2}{*}{ Violations } & Routine & $\begin{array}{l}\text { Bekerja tanpa memperhatikan SOP dan } \\
\text { Prosedur }\end{array}$ \\
\hline & & Exceptional & - \\
\hline \multirow{3}{*}{$\begin{array}{l}\text { Precondition } \\
\text { for unsafe } \\
\text { acts }\end{array}$} & \multirow{2}{*}{$\begin{array}{l}\text { Enviromental } \\
\text { Factors }\end{array}$} & $\begin{array}{l}\text { Physical } \\
\text { Environment }\end{array}$ & Bising \\
\hline & & $\begin{array}{l}\text { Technological } \\
\text { Environment }\end{array}$ & Clamp scarfing terlalu pendek \\
\hline & $\begin{array}{l}\text { Personal } \\
\text { Factors }\end{array}$ & $\begin{array}{l}\text { Crew Resource } \\
\text { management }\end{array}$ & - \\
\hline
\end{tabular}




\begin{tabular}{|c|c|c|}
\hline \multicolumn{2}{|c|}{ Kriteria HFACS } & SW \\
\hline \multirow{3}{*}{$\begin{array}{l}\text { Condition } \\
\text { of } \\
\text { Operators }\end{array}$} & Personal Readiness & - \\
\hline & $\begin{array}{l}\text { Adverse Mental } \\
\text { State }\end{array}$ & $\begin{array}{l}\text { Percaya diri yang berlebihan } \\
\text { Melamun/kurangnya kewaspadaan dalam } \\
\text { melakukan pengangkatan }\end{array}$ \\
\hline & $\begin{array}{l}\text { Adverse } \\
\text { Physiological State } \\
\text { Physical/Mental } \\
\text { Limitations }\end{array}$ & - \\
\hline \multirow{4}{*}{ Unsafe Supersion } & $\begin{array}{l}\text { Inadequate } \\
\text { Supervision }\end{array}$ & Kurangnya otoritas \\
\hline & $\begin{array}{l}\text { Planned } \\
\text { Inappropiate } \\
\text { Operations } \\
\end{array}$ & - \\
\hline & $\begin{array}{l}\text { Failure to Correct } \\
\text { Problem }\end{array}$ & $\begin{array}{l}\text { Gagal untuk mengidentifikasi bahaya } \\
\text { terkait dengan urangnya skill pekerja }\end{array}$ \\
\hline & $\begin{array}{l}\text { Supervisory } \\
\text { Violations } \\
\end{array}$ & - \\
\hline \multirow{3}{*}{ Organizational Influences } & $\begin{array}{l}\text { Resource } \\
\text { Management }\end{array}$ & - \\
\hline & $\begin{array}{l}\text { Organizational } \\
\text { Climate }\end{array}$ & - \\
\hline & $\begin{array}{l}\text { Organizational } \\
\text { Process }\end{array}$ & $\begin{array}{l}\text { Tidak ada pengertian secara jelas } \\
\text { mengenai apakah prosedur itu }\end{array}$ \\
\hline
\end{tabular}

Tabel 1 menunjukkan tabel analisis kecelakaan dengan korban yang berinisial SW dan AS yang telah diterapkan pada tahapan HFACS yaitu unsafe acts, precondition for unsafe acts, unsafe supervision dan organisational influences. Sebelumnya telah dijelaskan bahwa peneliti melakukan penelitian pada kejadian yang berulang.

Dari hasil analisis yang telah dilakukan pada korban SW dan AS dapat dilihat bahwa terdapat beberapa faktor yang menyebabkan terjadinya suatu kecelakaan. Suatu kesalahan atau error mendominasi sebagian besar data dari ecelakaan sedangkan pelanggaran/violations merupakan pengabaian yang disengaja untuk aturan dan peraturan yang mengatur K3. ${ }^{4}$ Faktor pertama ada pada tahap skill-based error yaitu tidak dapat memperioritaskan perhatian, pada tahap decision errors yaitu kurangnya pengetahuan tentang sistem dan prosedur.

Prosedur adalah suatu kegiatan klerikal, biasanya melibatkan beberapa orang dalam suatu departemen atau lebih, yang dibuat untuk menjamin penanganan secara seragam transaksi perusahaan yang terjadi berulang-ulang. ${ }^{5}$ Maka apabila pekerja kurang memahami prosedur maka akan mengganggu jalannya proses produksi karena pekerja berada dalam posisi dimana tingkat risiko terjadi kecelakaan lebih besar. 
Hampir sama dengan Decision Errors, salah persepsi mengenai pengertian prosedur itu sendiri termasuk dalam tahapan perceptual errors. Sedangkan kesalahan pada tahap routine violations yaitu bekerja tanpa memperhatikan prosedur. Hal ini berhubungan erat dengan kurangnya pengetahuan pekerja mengenai prosedur yang menyebabkan pekerja menjadi cenderung tidak memperhatikan prosedur yang telah dibuat.

Berikutnya adalah tahapan pada physical environment yaitu bising. Peningkatan suara dengan gelombang kompleks yang tidak beraturan dikenal sebagai bising. Bising merupakan salah satu stresor bagi individudan hal ini dapat menggangu konsentrasi para pekerja.

Bising yang berlebih, berulang kali didengar dan dalam jangka waktu yang lama dapat menimbulkan stress. ${ }^{6}$ Technological environment yaitu clamp scarfing yang terlalu pendek sehingga menyebabkan pekerja bekerja dengan tidak ergonomis karena harus melakukan pekerjaannya dengan posisi jongkok.

Adverse mental state merupakan suatu kondisi seseorang yang mempengaruhi kinerja yaitu hilangnya kesadaran situasional dimana melamun atau kurang kewaspadaan pada saat bekerja dan sikap yang merusak yaitu terlalu percaya diri, puas diri. $^{4}$ Failed to correct problem yaitu tidak dapat mengidentifikasi adanya bahaya terkait dengan skill pekerja. Selanjutnya adalah tahapan organisational process yaitu tidak adanya pengertian secara jelas tentang pengertian prosedur itu sendiri.

Dari analisa kecelakaan kemudian diklasifikasikan dengan HFACS dan mengklompokkan dalam bentuk grafik, sehingga dapat diketahui kesalahan atau pelanggaran yang dominan terjadi pada beberapa kasus yang telah dianalisis.

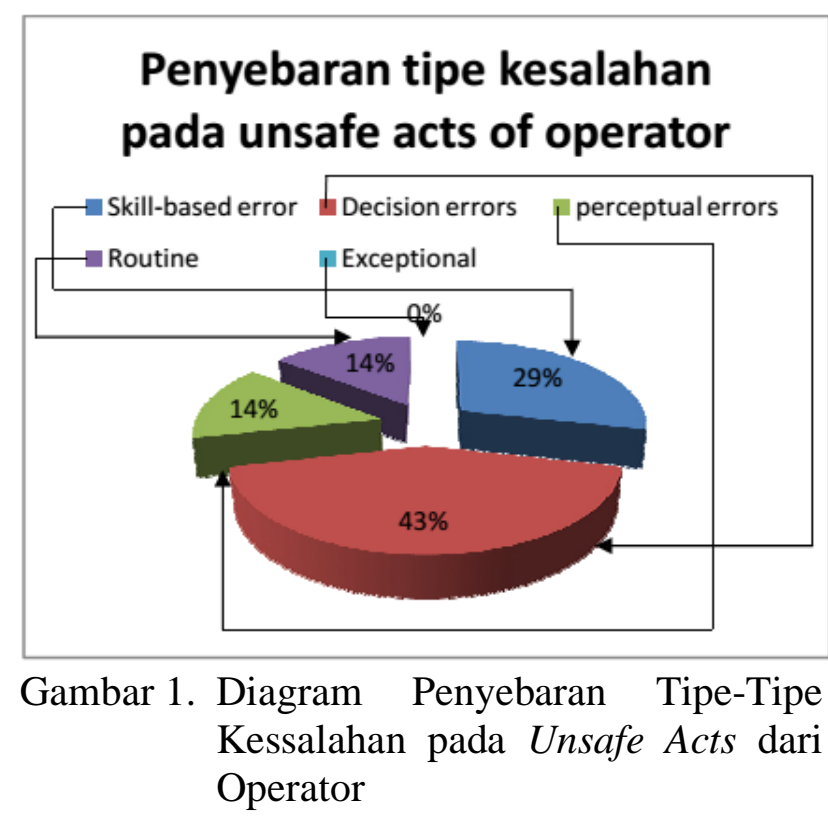

Gambar penyebaran tipe-tipe kesalahan menggambarkan bahwa Decision Error merupakan faktor utama yang menyebabkan tindakan tidak aman yang mengakibatkan kecelakaan. Kemudian berikutnya adalah skillbased error dengan $29 \%$ dan dengan prosentase yang sama yaitu $14 \%$ adalah routine violations dan perceptual errors sedangkan untuk exceptional $0 \%$ menunjukkan tidak adanya kegagalan atau kesalahan pada tahapan tersebut. 


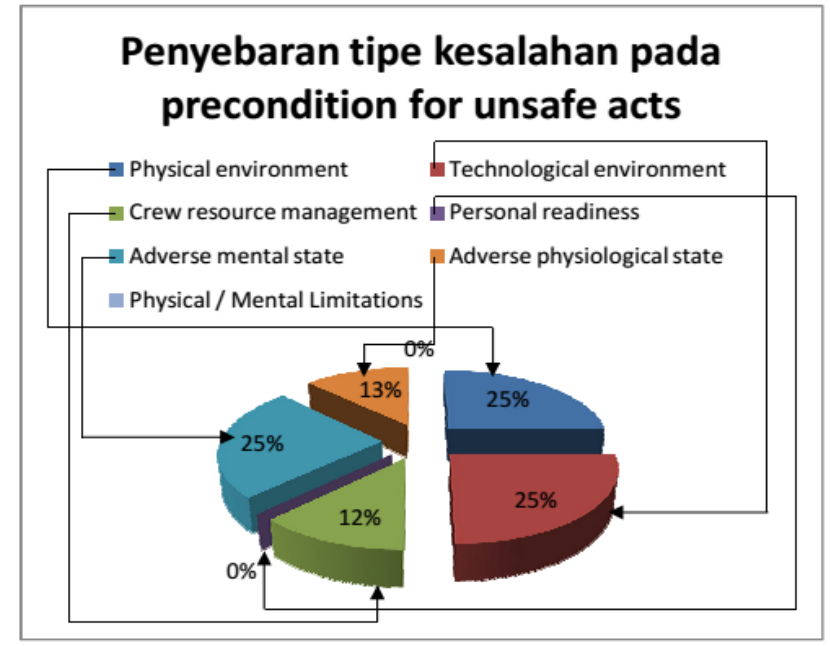

Gambar 2. Diagram Penyebaran Tipe-Tipe Kesalahan Precondition of Unsafe Acts

Grafik penyebaran tipe-tipe kesalahan pada precondition of unsafe acts menggambarkan bahwa ada 3 faktor utama yang merupakan kontribusi terbesar terhadap terjadinya kecelakaan, yaitu physical environment, technological environment dan adverse mental state dengan prosentase masing-masing sebesar $25 \%$. Beberapa faktor utama tersebut merupakan permasalahan yang serius.

Physical environment bisa menyebabkan tingkat konsentrasi pekerja berkurang, contoh dari Physical environment adalah kebisingan, pencahayaan, dll. ${ }^{4}$ Technological environment mencakup berbagai masalah termasuk desain peralatan dan kontrol yang apabila tidak terpenuhi maka akan mengganggu jalannya proses produksi. Sedangkan adverse mental state menjelaskan mengenai kondisi mental pekerja yang akan mempengaruhi kinerja contoh untuk adverse mental state adalah lengah, stress, terlalu percaya diri, lelah mental, dll.
Kemudian berikutnya adalah adverse physiological state sebesar $13 \%$ dan urutan berikutnya adalah crew resource management sebesar $12 \%$. Untuk personal readiness dan physical/mental limitation sebesar $0 \%$, hal ini menunjukkan bahwa sesungguhnya para pekerja memiliki kesiapan melakukan pekerjaannya.

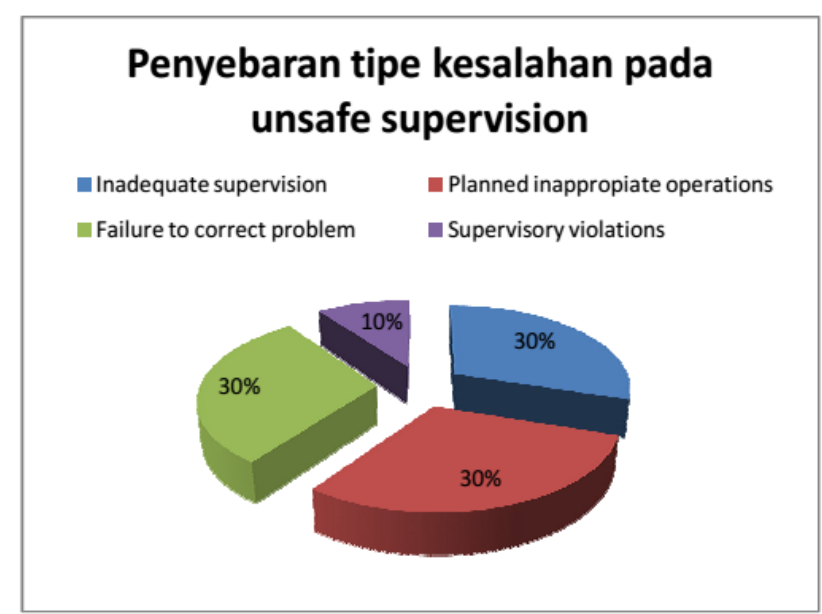

Gambar 3. Diagram Penyebaran Tipe-Tipe Kessalahan pada Unsafe Supervision

Gambar di atas menunjukkan bahwa kesalahan atau pelanggaran terjadi pada kurangnya tingkat pengawasan perencanaan yang tidak aman, kegagalan untuk memperbaiki kesalahan atau masalah yang ada, dan lemahnya pengawasan sebesar $30 \%$.

Peran pengawas adalah memastikan pekerjaan dilakukan secara aman dan efisien ${ }^{4}$. Pengawasan adalah hal penting dalam setiap organisasi yang sukses. Apabila pengawas melakukan pelanggaran maka ini akan menyebabkan para pekerja dalam kondisi yang berbahaya dimana resiko terjadinya kecelakaan sangat besar. 
Berikutnya adalah pelanggaran yang dilakukan pengawas, pelanggaran ini mengacu pada peraturan yang sengaja diabaikan oleh pengawas sebesar $10 \%$.

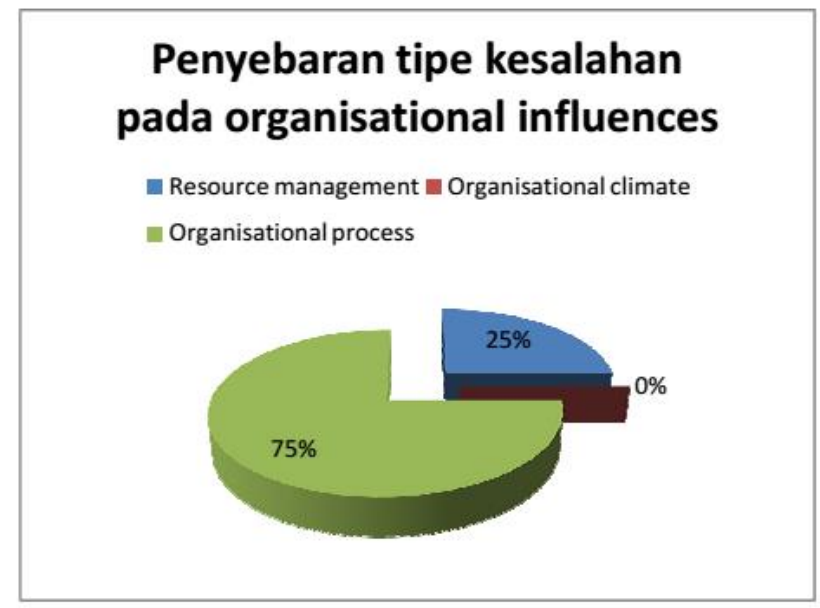

Gambar 4. Diagram Penyebaran Tipe-Tipe Kessalahan Pada Organisational Influences

Dari grafik penyebaran tipe kesalahan pada organisational influences dapat diketahui bahwa $75 \%$ kesalahan atau kegagalan ada pada organizational process. Contoh dari organizationnal process adalah tujuan jelas ditetapkan prosedur, intruksi prosedur, dll. 25\% kesalahan yang terjadi terletak pada resource management. Contoh resource management adalah membeli alat yang tidak sesuai, kurangnya peralatan, dll. Sedangkan kegagalan yang paling sering terjadi diantara tahapan HFACS adalah precondition of operators. Precondition of operators merupakan sebuah kondisi yang memacu terjadinya Unsafe Act seperti kelelahan mental atau buruknya komunikasi antar operator di dalam sebuah system. ${ }^{4}$ Berikut adalah grafik penyebaran kesalahan untuk 4 (empat) tipe kegagalan HFACS.

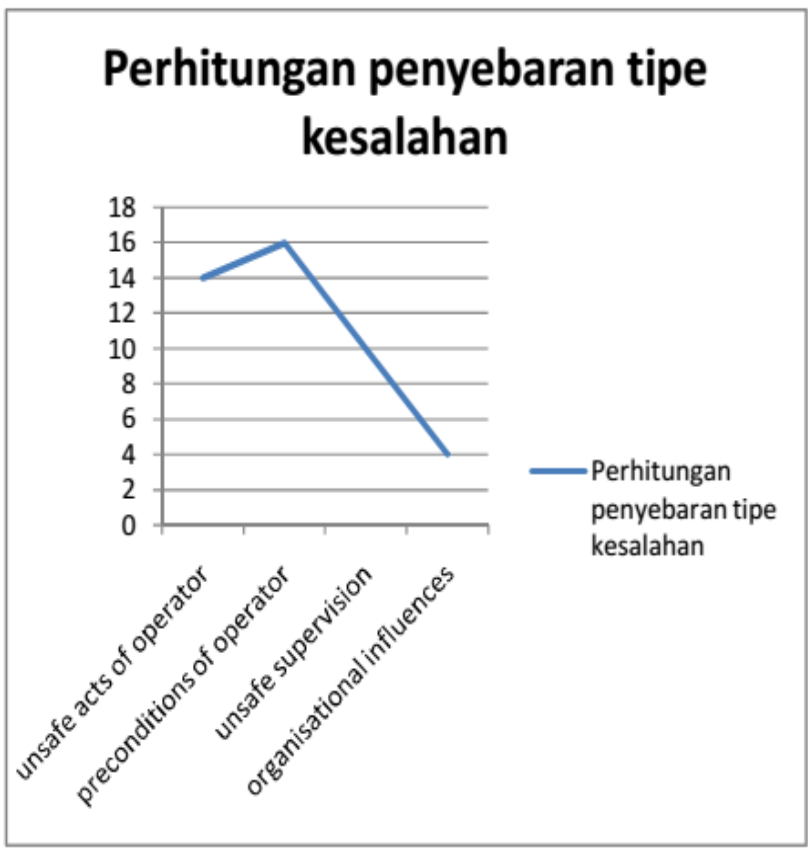

Gambar 5. Diagram Penyebaran Tipe-Tipe Kesalahan

\section{Hubungan Kegagalan pada Tiap Level HFACS}

Langkah berikutnya adalah untuk mengetahui asosiasi pada kegagalan antara tiap tahapan HFACS menggunakan uji koefisien kontingensi. Uji koefisien kontingensi digunakan untuk menghitung hubungan antar variabel bila datanya berbentuk nominal. ${ }^{3}$

Berikut ini adalah tabel data variabel yang akan digunakan untuk menguji hubungan di tiap tahapan HFACS. 
Tabel 2. Data Variabel untuk Uji Koefisien Kontingensi (C)

\begin{tabular}{|c|c|c|c|c|c|}
\hline \multicolumn{3}{|c|}{ Kriteria HFACS } & Kasus 1 & Kasus 2 & Kasus 3 \\
\hline \multirow{5}{*}{ Unsafe acts } & \multirow{3}{*}{ Errors } & $\begin{array}{l}\text { Skill-based } \\
\text { errors }\end{array}$ & 2 & 2 & 2 \\
\hline & & $\begin{array}{l}\text { Decision } \\
\text { errors }\end{array}$ & 2 & 1 & 1 \\
\hline & & $\begin{array}{l}\text { Perceptual } \\
\text { errors }\end{array}$ & 2 & 2 & 1 \\
\hline & \multirow{2}{*}{ Violations } & Routine & 2 & 1 & 2 \\
\hline & & Exceptional & 1 & 1 & 2 \\
\hline \multirow{7}{*}{$\begin{array}{l}\text { Preconditions } \\
\text { for unsafe acts }\end{array}$} & \multirow{2}{*}{$\begin{array}{l}\text { Environmental } \\
\text { factors }\end{array}$} & $\begin{array}{l}\text { Physical } \\
\text { environment }\end{array}$ & 2 & 2 & 1 \\
\hline & & $\begin{array}{l}\text { Technological } \\
\text { environment }\end{array}$ & 2 & 2 & 1 \\
\hline & \multirow{2}{*}{$\begin{array}{l}\text { Personel } \\
\text { factors }\end{array}$} & $\begin{array}{l}\text { Crew resource } \\
\text { management }\end{array}$ & 1 & 2 & 2 \\
\hline & & $\begin{array}{l}\text { Personel } \\
\text { readiness }\end{array}$ & 1 & 1 & 1 \\
\hline & \multirow{3}{*}{$\begin{array}{l}\text { Condition of } \\
\text { operators }\end{array}$} & $\begin{array}{l}\text { Adverse } \\
\text { mental state }\end{array}$ & 2 & 2 & 2 \\
\hline & & $\begin{array}{l}\text { Adverse } \\
\text { physiological } \\
\text { states }\end{array}$ & 1 & 2 & 1 \\
\hline & & $\begin{array}{l}\text { Physical / } \\
\text { mental } \\
\text { limitations }\end{array}$ & 1 & 1 & 1 \\
\hline \multirow{4}{*}{$\begin{array}{c}\text { Unsafe } \\
\text { supervision }\end{array}$} & \multicolumn{2}{|c|}{ Inadequate supervision } & 2 & 2 & 1 \\
\hline & \multicolumn{2}{|c|}{$\begin{array}{l}\text { Planned inappropiate } \\
\text { operationns }\end{array}$} & 1 & 1 & 1 \\
\hline & \multicolumn{2}{|c|}{ Failure to correct problem } & 2 & 2 & 2 \\
\hline & \multicolumn{2}{|c|}{ Supervisory violations } & 1 & 1 & 2 \\
\hline \multirow{3}{*}{$\begin{array}{l}\text { Organisational } \\
\text { influences }\end{array}$} & \multicolumn{2}{|c|}{ Resource management } & 1 & 1 & 2 \\
\hline & \multicolumn{2}{|c|}{ Organizational climate } & 1 & 1 & 1 \\
\hline & \multicolumn{2}{|c|}{ Organizational process } & 2 & 2 & 1 \\
\hline
\end{tabular}

Sebelumnya telah dijelaskan bahwa skala yang digunakan dalam uji fisher's exact adalah data berskala nominal. Pada tabel diatas dapat dilihat bahwa terdapat 2 angka yaitu angka 1 dan 2. Dimana angka 1 merupakan angka yang menunjukkan bahwa tidak ada kegagalan pada tahapan tersebut, sedangkan untuk angka 2 maka terdapat kegagalan pada tahapan HFACS.

Setelah memberikan kode kepada masingmasing kasus di tiap tahapan HFACS langkah berikutnya adalah melakukan uji koefisien kontingensi.

$\mathrm{H}_{0}$ : Tidak ada asosiasi antar tahapan HFACS

$\mathrm{H}_{1}$ : Ada asosiasi antar tahapan HFACS

Taraf sifnifikansi yang digunakan adalah $10 \%(\alpha=0,10)$, dimana jika nilai probabilitas (signifikansi) $<0,10$ maka $\mathrm{H}_{0}$ ditolak atau $\mathrm{H}_{1}$ diterima. Dari uji kontingensi koefisien (C) maka asosiasi yang signifikan dapat Digambarkan seperti berikut: 


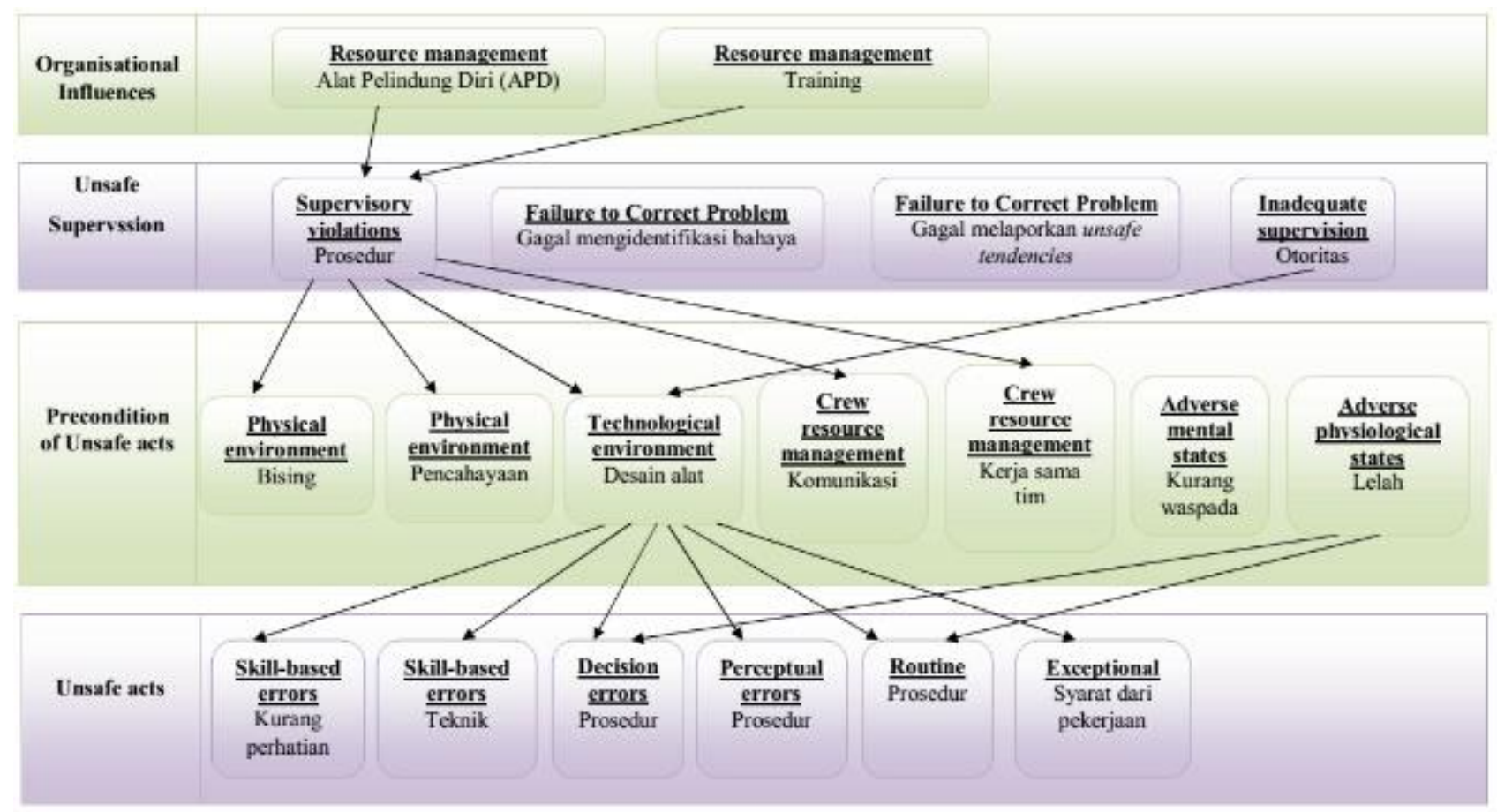

Gambar 6. Hubungan antar Tahapan

\section{SIMPULAN DAN SARAN}

\section{Simpulan}

Berdasarkan analisis menggunakan metode HFACS, diperoleh kesimpulan bahwasannya terdapat 12 Loss Time Accident (LTA), 38 First Aid Injury (FAI) dan 5 near miss. Ditemukan human factors pada kejadian berulang di semua tahapan HFACS, yaitu untuk tahapan unsafe acts of operator adalah decision errors; untuk tahapan preconditions for unsafe acts adalah physical environment, technological environment dan adverse mental state; untuk tahapan unsafe supervision adalah lemahnya pengawasan; untuk organisational influences ada pada organisational process.

Dari hasil uji kontingensi koesfisien (C) dapat disimpulkan bahwa dalam kasus ini hampir semua elemen yang terdapat pada tahapan HFACS saling memengaruhi.

\section{Saran}

Rekomendasi yang dapat diberikan kepada perusahaan, yaitu pekerja harus lebih proaktif terhadap keamanan dan keselamatan bekerjanya; pengawas seharusnya membangun komunikasi yang baik dengan pekerja; dan organisasi seharusnya melakukan beberapa kajian ulang dan pemantauan terhadap jalannya proses produksi.

\section{REFERENSI}

1. Hughes P. \& Ferrett E. Introduction to Health and Safety at Work. In: Slovenia. s.1.:s.n. 2009.

2. Ivancevich, J. M. \& Matteson, M. T. Organizational Behaviour and Management. Singapore: s.n. n.d. 
MTPH Journal, Volume 4, No. 1, March 2020

ISSN: 2549-189X; e-ISSN: 2549-2993

3. Kementrian Tenaga Kerja dan Transmigrasi RI, 2013. In: s.1.:s.n.

4. Mulyadi. Akuntansi Biaya, Edisi ke 5. In: Yogyakarta: YKPN, STIE. 2009.

5. Wiegmann D. A. \& Shappel S. A, A. Human Error Approach to Aviation Accident Analysis. In: UK. s.l.:s.n. 2005. 